\author{
Nataliia Kholiavko \\ D.Sc. (Economics), Associate Professor, \\ Department of Finance, Banking and Insurance \\ Chernihiv Polytechnic National University, Chernihiv, Ukraine \\ E-mail: nateco@meta.ua \\ ORCID: https://orcid.org/0000-0003-2951-7233

\section{Antonina Djakona} \\ Dr.oec., Associate Professor \\ Vice-Rector for Development and Innovations, Head of Marketing Department \\ ISMA University of Applied Sciences, Riga, Latvia \\ E-mail: antonina.djakona@isma.lv \\ ORCID: https://orcid.org/0000-0002-4089-9335
}

\title{
Higher education as a driver of the digital economy development
}

\begin{abstract}
The purpose of the current study is to analyze the impact of higher education and universities on the dynamics of the digital economy. The authors hypothesized to distinguish three components (educational, research, innovation) in the digital economy development. Within this article, the results of using index and cluster analysis methods to determine the impact of the educational component on the processes of digital economy development in Ukraine at the macroeconomic and meso-economic levels are presented. The special attention is put on the educational component because the higher educational institutions concentrate intellectual capital of the country, as well as prepare future specialists for the needs of digital economy. Moreover the universities' scientists make an impact on digital economy development by conducting research and transferring their results technological innovations, information and communicational technologies, etc.) into the real economy. During the research, main problems of digital economy development, determined by the poor quality of educational services, insufficient commercialization of university research results in the real economy, are identified. The authors conclude that solving the identified problems requires synchronization of interests and establishing a long-term partnership between universities, business, the state and the public. Importance of optimizing the state regulatory influence on economic entities in the context of digitalization of the national economy is emphasized. In particular, it is proposed to group the set of measures of state regulation into three vectors, namely: neutral-encouraging (support of positive dynamics of intensive development), incentive-providing (resource and information support of development processes) and initiative-mentoring (motivation and coordination of development processes).
\end{abstract}

DOI: https://doi.org/10.30525/2500-946X/2021-1-14

\section{Statement of the problem}

Revitalization of the processes of the national economy informatization leads to an increase of the higher education role as a system of training highly qualified personnel for the national economy and generation of new knowledge, information, innovative technologies. Processes of the information society development present complex tasks and challenges, requiring higher education institutions to be prepared to function productively and effectively in the new environment. In our study, we hypothesize that there is a mutual influence of higher education and the digital economy. On the one hand, digital economy poses specific challenges to the higher education system, transforming its activities, in particular, the following challenges include the following: dynamization of social and economic processes; transformation of knowledge into productive power and product; spread of ICT; creation of a global information field; virtuali-zation of workplaces; exacerbation of problems of information security and protection of intellectual property rights.

\section{Keywords}

Digital economy, digitalization, higher education, university, $\mathrm{k}$-means algorithm, index method

JEL: I21, I22, O11
On the other hand, higher education systems and universities play a decisive role in the processes of formation and development of the digital economy, since they determine the dynamics of its individual structural components. It is the institutions of higher education that prepare the next generation of workers who have digital competencies, are media literate, capable of generating innovations and rapidly adapting to work with the latest technologies (Cosmulese, Grosu, et.al., 2019). In addition, universities concentrate powerful intellectual capital, enabling them to carry out high-quality research, make scientific discoveries and innovations, with their further commercialization in the real sector of the national economy (Bekkers, Bodas Freitas, 2008; Ivanov, Tyshchenko, 2015). The University-Business Partnership promotes integration of higher education institutions into innovative business chains; enhancing their competitiveness by responding promptly to current requests from the real sector of the national economy; intensification of innovative development of the business sector, expansion of access of economic subjects to the latest scientific developments, 
discoveries, information, professional consultations, expertise and more.

The purpose and problem of research is to analyze the impact of higher education and universities on the dynamics of the digital economy.

Latest scientific progress and publications review. Within this article, we present the results of the index and cluster analysis of the higher education impact on the processes of digital economy formation and development in Ukraine. These methods of analysis are widely used in economic research.

Out of all the clustering methods of the objects set, we'll dwell on the k-means algorithm (Pankaj, Agarwal, Nabil H. Mustafa, 2004). Proposed by J. Hartigan and M. Wong, this algorithm is nowadays widely used because it is characterized by efficiency, relative simplicity and sufficient efficiency of the obtained results. The basic idea of the algorithm is to divide the set of observations into clusters so that the averages of the cluster are as different as possible from each other; keep the distances (differences) between objects of one class minimal; maximize the distance between objects of different classes; minimize the total quadratic deviation of cluster points from centroids.

Strengths of the k-means algorithm include the following advantages: testability, speed and ease of use, possibility of calculations automation, clarity of the algorithm and results of the analysis. At the same time, it should be noted that there are some limitations of the selected clustering method, namely: high sensitivity to factors affecting cluster averages; difficulties in processing large databases; the use of continuous, not discrete, data.

In general, the methodology is sufficiently deep in the scientific literature and peculiarities of using the $\mathrm{k}$-means algorithm in the clustering of multiple objects are characterized (Artuhur, Vassilvitskii, 2006; HarPeled, Sadri, 2005). Kanungo T. et al. (2004) formulated an approach to the implementation of a simple k-means algorithm, which features are practical considerations and difficulties that may arise during the direct use of such an algorithm when solving specific application problems (Kanungo, Mount, Netanyahu, Piatko, Silverman, Wu, 2004). Artuhur D. and Vassilvitskii S. (2006) propose an approach to the estimation of the k-means algorithm, in particular in terms of calculating the duration of the preparation procedure and actually performing the analysis using this method. Issues of the acceleration of the $\mathrm{k}$-means algorithm and reduction of the quantization error are discussed by Bottou L. and Bengio Y. in joint scientific work (1995).

Elkan C. (2003) developed an accelerating clustering algorithm with the emphasis on maintaining a satisfactory level of accuracy of the results obtained. Testing this algorithm in practice proved its applicability in the analysis of large samples of objects (up to 1000 measurements).

Publication of Sculley D. (2010) is devoted to the modifications to the $\mathrm{k}$-means algorithm that are able to optimize the method of using this algorithm, reduce its cost, and eliminate the difficulty of using web applications to cluster objects using this method.

In our opinion, the k-means algorithm can be applied for clustering the regions of Ukraine according to the level of the development of the educational component of the digital economy. Its use made it possible to deepen significantly the results of the index analysis, creating prerequisites for identifying regional disparities and peculiarities in the dynamics of the educational component of the digital economy.

Methodology. By conducting the study, we proceeded from several hypotheses:

1) analytical characterization of the processes of formation and development of the digital economy should be implemented on the basis of the interdisciplinary approach;

2 ) in-depth analysis of the outlined processes requires a combination of the index and cluster methods, which will provide an opportunity to identify the main trends and regional features of the digital economy development in Ukraine;

3) development of the digital economy is determined by the dynamics of three interconnected components - education, innovation and research. The educational component characterizes the development of the intellectual and human resources potential of the digital economy development; the research component - formation of the background of the digital economy development in the medium and long term; the innovative component implementation of the existing potential in the national economy. Within this article, attention is focused on the analysis of the impact of the educational component on the digital economy dynamics.

The methodical approach, used in the course of the study, is described in detail in the table 1.

The following basic prerequisites are the basis for developing a methodological approach to assessing the impact of the educational component on the dynamics of the digital economy: taking into consideration actual social and economic, and scientific-technical tendencies of the Ukraine's development; use of partial indicators which constituent parameters are publicly available in official statistical databases; considering the factors of exogenous and endogenous environment that can influence the educational component of the digital economy development.

\section{Results of the research}

Index analysis of the impact of the educational dominant on the digital economy development. The first block of the developed methodological approach to assessing the impact of the educational component on the digital economy dynamics is the application of the index analysis method and interpretation of its results. For the purpose of the index analysis, we selected a set of indicators that are, first of all, available in the public domain; secondly, they are provided by the national statistical office and are officially confirmed; thirdly, are represented by the statistical office in dynamics (at least for the last 10 years of observation). In particular, these are the indicators that characterize the capacity of universities (the number of higher education institutions $-\mathrm{E}_{1}$, including those with doctoral degrees E6 and postgraduate degree $-\mathrm{E}_{7}$ ), their contribution to the human resources development of the economy at the stage of its informatization (the number of students of higher education institutions $-\mathrm{E}_{2}$, number of postgraduate students $-E_{3}$, number of doctoral students $-E_{4}$, number of students per 10 thousand people $-\mathrm{E}_{8}$ ), financial aspects (amount of consolidated higher education expenditures $-E_{5}$ ). The above list of the used indicators has certain limitations due to the imperfection of the current statistical base, as well as the fact that a number of university performance results cannot be fully quantified. Calculations made are presented in tables 2-4. 
TABLE 1 Characteristic of the methodological approach to the assessment of the impact of the educational component on the digital economy development

\begin{tabular}{|c|c|c|}
\hline Stage & Essence of the stage & Characteristic of the stage \\
\hline & & Index analysis \\
\hline 1 & $\begin{array}{l}\text { Determining the } \\
\text { structure of the complex } \\
\text { integral index }\end{array}$ & Educational, innovation, and research components of the digital economy development are highlighted \\
\hline 2 & $\begin{array}{l}\text { Determination of } \\
\text { the system of partial } \\
\text { indicators for the } \\
\text { characterization of } \\
\text { components in the } \\
\text { complex index }\end{array}$ & $\begin{array}{l}\text { Educational component (is analyzed within this article): the number of higher education institutions (including } \\
\text { those with doctoral and postgraduate studies), students (including, per 10,000 population), graduate students, } \\
\text { doctoral students, the amount of consolidated budget expenditures for higher education. } \\
\text { Innovation component: share of innovation-driven and innovation-active enterprises, number of new technological } \\
\text { processes implemented, introduction volume of innovative types of products, expenses amount for innovative } \\
\text { activity of industrial enterprises, share of innovative products sold in industrial volume, number of contracts for the } \\
\text { disposal of industrial property rights, number of applications for inventions from national applicants. } \\
\text { Research component: number of organizations performing R\&D, number of scientists, expenditures amount } \\
\text { for R\&D, proportion of the volume of R\&D performed in GDP; share of the higher education sector among } \\
\text { R\&D organizations; share of the higher education sector in R\&D funding; number of doctors and candidates of } \\
\text { sciences in economics. }\end{array}$ \\
\hline 3 & $\begin{array}{l}\text { Choosing a method for } \\
\text { constructing the complex } \\
\text { index }\end{array}$ & $\begin{array}{l}\text { - product method: } \\
\text { I- integrated index; } \\
\mathrm{X}_{\mathrm{i}} \text { - rated value; } \\
\mathrm{n} \text { - number of variables } \\
\text { - amounts method: } \\
\mathrm{X}_{\mathrm{i}_{1}} \text { - integrated index in the current period; } \\
\mathrm{X}_{\mathrm{i}_{0}} \text { - integrated index in the basic period; } \\
\text { - geometric mean method: } \\
\qquad \sum_{\mathrm{i}=1}^{\mathrm{n}} \frac{\mathrm{X}_{\mathrm{i}_{1}}}{\mathrm{X}_{\mathrm{i}_{0}}}=\sum_{\mathrm{i}=1}^{\mathrm{n}} \mathrm{X}_{\mathrm{i}}, \\
\Delta \mathrm{X}_{\mathrm{i}} \text { - absolute deviation of the actual value of the integrated index (in the current period) from the value in the } \\
\text { basic period (Prokopenko, Ganin, 2008) }\end{array}$ \\
\hline 4 & $\begin{array}{l}\text { Generation of an array } \\
\text { of statistics on identified } \\
\text { partial indexes }\end{array}$ & $\begin{array}{l}\text { Since the selected variables are grouped by components, we have different weighting factors. Accordingly, the } \\
\text { integrated index is calculated as follows: } \\
\qquad \mathrm{I}=\sqrt{\sum_{\mathrm{i}=1}^{\mathrm{n}} \mathrm{R}_{\mathrm{j}}\left(\Delta \mathrm{X}_{\mathrm{ij}}\right)^{2}} \\
\Delta \mathrm{R}_{\mathrm{ij}}-\text { - absolute deviation of the actual value of the integrated index of the } \mathrm{j} \text {-criterion in the current period from } \\
\text { the value in the basic period (Dubrov, Mxytaryan, Troshyn, 1998) }\end{array}$ \\
\hline 5 & $\begin{array}{l}\text { Determination of the } \\
\text { weight of each partial } \\
\text { index in the respective } \\
\text { components }\end{array}$ & $\begin{array}{l}\text { Under the method of the hierarchy analysis by Saaty T.: } \\
\text { - drawing up a matrix of pairwise comparisons to construct a hierarchy of indexes by the degree of influence on } \\
\text { the relevant components of a complex integrated index; } \\
\text { - construction of spreadsheets for determining weights (Saaty, 1980) }\end{array}$ \\
\hline 6 & $\begin{array}{l}\text { Formalization of isolated } \\
\text { components. Rationing } \\
\text { of analytical indicators }\end{array}$ & $\begin{array}{l}\text { Matrix creation of standardized } \\
\qquad Z_{i j}=\frac{X_{i j}-\bar{X}_{j}}{S_{j}} \\
\text { values: } \\
\mathrm{X}_{\mathrm{ij}} \text { - absolute value of the indicator over the timer, and, } \\
\mathrm{X}_{\mathrm{j}} \text { - average value of the indicator; } \\
\mathrm{S}_{\mathrm{j}} \text { - standard error of the mean of the indicator } \mathrm{X}_{\mathrm{ij}}(\mathrm{Kym}, \text { Dzh.-O., 1989) }\end{array}$ \\
\hline 7 & \multicolumn{2}{|c|}{$\begin{array}{l}\text { Calculation of sub-indices of a complex indicator by assessment of the digital economy development in terms of three components in the } \\
\text { dynamics }\end{array}$} \\
\hline 8 & \multicolumn{2}{|c|}{ Calculation of predictive values of sub-indices of a complex indicator } \\
\hline 9 & $\begin{array}{l}\text { Construction of a } \\
\text { complex integrated index }\end{array}$ & $\begin{array}{l}\text { as a weighted average educational, innovation, scientific and technical component with weights based on the } \\
\text { Saaty method }\end{array}$ \\
\hline
\end{tabular}


(End of Table 1)

\begin{tabular}{|c|c|c|}
\hline \multicolumn{2}{|r|}{ Essence of the stage } & \multirow{2}{*}{$\begin{array}{l}\text { Characteristic of the stage } \\
\text { Cluster analysis }\end{array}$} \\
\hline & & \\
\hline 1 & Initial block & $\begin{array}{l}\text { 1) selection of starting points (centers) of clusters; } \\
\text { 2) assigning each object of a set of observations to the respective clusters; }\end{array}$ \\
\hline 2 & Correcting block & $\begin{array}{l}\text { 1) calculation of cluster centers; } \\
\text { 2) calculation of distances between each object of the analyzed amount and the cluster centers; } \\
\text { 3) moving previous cluster centers into centroids; } \\
\text { 4) iterations on the redistribution of objects between clusters to stabilize cluster centers (Jain, Murty, \& Flynn, } \\
\text { 1999) }\end{array}$ \\
\hline 3 & Testing block & $\begin{array}{l}\text { 1) calculation of mean values for each cluster; } \\
\text { 2) assessment of the clustering quality }\end{array}$ \\
\hline \multicolumn{3}{|r|}{ System analysis } \\
\hline 1 & \multicolumn{2}{|c|}{ Synthesis of the results of the index and cluster analysis } \\
\hline 2 & \multicolumn{2}{|c|}{ Formulation of conclusions and suggestions } \\
\hline
\end{tabular}

Source: compiled by the authors

Using the data in tables 1-3 allowed obtaining an analytical expression of the index of the educational component of the digital economy development (1):

Iedu $=0,06 E_{1}+0,1 E_{2}+0,15 E_{3}+0,19 E_{4}+0,19 E_{5}+$

$+0,09 E_{6}+0,08 E_{7}+0,14 E_{8}$

Interim calculations for the values quantitation of the analyzed indicators are given in tables 5-6.

Graphical interpretation of the results is given in Figure 1. Data on the point forecast of the indicators values of the educational component of the digital economy are given in table 7.

Index dynamics of the educational component of the digital economy development presented in the chart (see Figure 1) shows a colossal decline in 2014. The main reasons of this decline are the following:

- data lack in the official statistical database of the temporarily occupied territories of the Autonomous Republic of Crimea, the cities of Sevastopol, Donetsk and Luhansk regions, starting in 2014;

- demographic situation, which leads to a decrease in the number of university entrants and applicants in the country;

- migration processes, which are manifested, on the one hand, in the departure of young people to study at foreign universities; on the other hand, in the departure of scientific staff to work abroad;

- low prestige of the profession of scientist in Ukrainian society;

- low level of competitiveness of domestic universities in the global educational space;

- lack of funding for higher education institutions in Ukraine, low level of diversification of funding sources;

- complication of the geopolitical situation in the country, which exacerbates social and economic problems and adversely affects the solvency of the population (including as consumers of higher education institutions) and others.

In summary, it should be noted that the results obtained from the application of the index analysis indicate a significant impact of the educational component on the processes of formation and development of the digital economy. This is logical given the fact that higher education institutions provide training for people capable of acting and thinking innovatively, and research aimed at generating innovation and producing the latest technology are carried out. In other words, universities prepare the basis not only for staffing the development of the digital economy in the country, but also lay the foundation for innovative development of the national economy, creating prerequisites for the introduction of the latest information and communication technologies into the activities of business entities.

In our opinion, it is advisable to support the digital economy development based on stimulating the educational component at the national level. In fact, higher education institutions manage to integrate educational, research and innovation activities, and ensure the transfer of commercially attractive scientific results to the real sector of the national economy.

Cluster analysis of the impact of the educational dominant of the digital economy development. The second block of the offered methodological approach is carrying out the cluster analysis. This method will allow us to classify objects by class based on their similarity criterion (Wu, Kumar, 2009). In this way, we will be able to analyze not each object individually, but perform an in-depth analysis of the set of objects, identify regional disparities and regional peculiarities of the impact of the educational component on the dynamics of the digital economy development. In the course of clustering, we used the k-means algorithm, which refers to non-hierarchical methods, which is an iterative method of dividing a set of data $m$ into a given number of clusters $\mathrm{k}(\mathrm{k} \leq \mathrm{m})$.

Given shortcomings of the existing statistical base, we were forced to make some changes to the structure of parameters used in the analysis of the impact of the educational component on the dynamics of the digital economy; in particular, we replaced some partial indicators that do not have official regional statistics in annual dynamics. Therefore, the structure of the educational component of the digital economy development within the framework of this block of approbation of the methodological approach is as follows: $\mathrm{Er}_{1}$ - number of higher education institutions of III-IV accreditation levels, pcs.; $\mathrm{Er}_{2}$ - number of students of higher education institutions of III-IV accreditation levels, persons; $\mathrm{Er}_{3}-\mathrm{PhD}$ number, persons; $\mathrm{Er}_{4}$ - number of postgraduate students, persons; $\mathrm{Er}_{5}$ - number of employees involved in the $R \& D$ implementation who have received higher education, persons; $\mathrm{Er}_{6}$ - number of higher education 
TABLE 2 Matrix of paired comparisons for hierarchy of indicators

on the impact degree of the educational component on the digital economy development

\begin{tabular}{|c|c|c|c|c|c|c|c|c|}
\hline Indicator & $\mathbf{E}_{1}$ & $\mathbf{E}_{2}$ & $\mathbf{E}_{3}$ & $\mathbf{E}_{4}$ & $\mathbf{E}_{5}$ & $\mathbf{E}_{6}$ & $\mathbf{E}_{7}$ & $\mathbf{E}_{8}$ \\
\hline $\mathbf{E}_{1}$ & 1 & 0,2 & 0,2 & 0,2 & 0,33333333 & 0,5 & 0,5 & 2 \\
\hline $\mathbf{E}_{2}$ & 5 & 1 & 0,25 & 0,25 & 0,5 & 1 & 1 & 0,5 \\
\hline $\mathbf{E}_{3}$ & 5 & 4 & 1 & 0,5 & 0,33333333 & 1 & 1 & 0,5 \\
\hline $\mathbf{E}_{4}$ & 5 & 4 & 2 & 1 & 0,33333333 & 2 & 2 & 0,5 \\
\hline $\mathbf{E}_{5}$ & 3 & 2 & 3 & 3 & 1 & 2 & 2 & 1 \\
\hline $\mathbf{E}_{6}$ & 2 & 1 & 1 & 0,5 & 0,5 & 1 & 1 & 1 \\
\hline $\mathbf{E}_{7}$ & 2 & 1 & 1 & 0,5 & 0,5 & 1 & 1 & 0,33333 \\
\hline $\mathbf{E}_{8}$ & 0,5 & 2 & 2 & 2 & 1 & 1 & 3 & 1 \\
\hline
\end{tabular}

Source: compiled by the authors

TABLE 3 Calculation table for determining the weights by the Saaty hierarchy method (educational component)

\begin{tabular}{|c|c|c|c|c|c|c|c|c|c|c|c|c|}
\multicolumn{1}{c}{ Indicator } & $\mathbf{E}_{1}$ & $\mathbf{E}_{2}$ & $\mathbf{E}_{3}$ & $\mathbf{E}_{4}$ & $\mathbf{E}_{5}$ & $\mathbf{E}_{6}$ & & $\mathbf{E}_{7}$ & $\mathbf{E}_{8}$ \\
\hline Total value of the indicator & 23,5 & 15,2 & 10,45 & 7,95 & 4,5 & 9,5 & 11,5 & 6,83333333 \\
\hline
\end{tabular}

Source: compiled by the authors

TABLE 4 Results of determining weights by the Saaty hierarchies method

\begin{tabular}{|c|c|c|c|c|c|c|c|c|}
\hline Indicator & $E_{1}$ & $\mathbf{E}_{2}$ & $\mathbf{E}_{3}$ & $\mathbf{E}_{4}$ & $\mathbf{E}_{5}$ & $E_{6}$ & $\mathbf{E}_{7}$ & $\mathbf{E}_{8}$ \\
\hline Weighting factor & 0,06 & 0,10 & 0,15 & 0,19 & 0,19 & 0,09 & 0,08 & 0,14 \\
\hline
\end{tabular}

Source: compiled by the authors

TABLE 5 Quantitative values of indicators for determining the index of the educational component of the digital economy development

\begin{tabular}{|c|c|c|c|c|c|c|c|c|}
\hline Year & $\mathbf{E}_{1}$ & $\mathbf{E}_{2}$ & $\mathbf{E}_{3}$ & $\mathbf{E}_{4}$ & $\mathbf{E}_{5}$ & $\mathbf{E}_{6}$ & $\mathbf{E}_{7}$ & $\mathbf{E}_{8}$ \\
\hline 2001 & $-0,38$ & $-0,87$ & $-1,55$ & $-1,65$ & $-1,37$ & $-1,56$ & 0,14 & $-1,99$ \\
\hline 2002 & 0,07 & $-0,49$ & $-1,26$ & $-1,40$ & $-1,01$ & $-1,38$ & 0,06 & 0,82 \\
\hline 2003 & 0,41 & $-0,07$ & $-0,75$ & $-1,18$ & $-0,85$ & $-1,20$ & $-0,02$ & 0,70 \\
\hline 2004 & 0,72 & 0,43 & $-0,39$ & $-0,97$ & $-0,69$ & $-1,01$ & $-0,10$ & 0,58 \\
\hline 2005 & 0,64 & 0,91 & 0,01 & $-0,79$ & $-1,45$ & $-0,83$ & $-0,18$ & 0,46 \\
\hline 2006 & 0,83 & 1,22 & 0,41 & $-0,56$ & 0,09 & $-0,55$ & 0,35 & 0,34 \\
\hline 2007 & 0,87 & 1,37 & 0,74 & $-0,37$ & $-0,91$ & 0,30 & 1,05 & 1,31 \\
\hline 2008 & 0,94 & 1,34 & 0,98 & $-0,14$ & $-0,28$ & $-0,27$ & 1,23 & 1,09 \\
\hline 2009 & 0,83 & 1,02 & 1,19 & $-0,19$ & $-0,02$ & 0,02 & 1,93 & 0,87 \\
\hline 2010 & 0,79 & 0,71 & 1,34 & 0,21 & 0,43 & 0,49 & 0,70 & 0,56 \\
\hline 2011 & 0,64 & 0,23 & 1,21 & 0,50 & 0,61 & 0,21 & $-0,01$ & 0,41 \\
\hline 2012 & 0,22 & $-0,12$ & 1,06 & 1,24 & $-0,01$ & 0,30 & 0,35 & $-0,05$ \\
\hline 2013 & $-0,12$ & $-0,39$ & 0,46 & 1,31 & 0,98 & 0,58 & $-0,01$ & $-0,42$ \\
\hline 2014 & $-1,93$ & $-1,16$ & $-0,61$ & 1,02 & $-0,07$ & 0,21 & $-2,30$ & $-0,68$ \\
\hline 2015 & $-1,52$ & $-1,33$ & $-0,37$ & 1,27 & 1,09 & 1,62 & $-0,71$ & $-1,36$ \\
\hline 2016 & $-1,55$ & $-1,35$ & $-1,07$ & 1,15 & 1,55 & 1,53 & $-1,24$ & $-1,52$ \\
\hline 2017 & $-1,48$ & $-1,46$ & $-1,40$ & 0,56 & 1,93 & 1,53 & $-1,24$ & $-1,12$ \\
\hline 2018 & $-1,48$ & $-1,46$ & $-1,40$ & 0,56 & 1,93 & 1,53 & $-1,24$ & $-1,12$ \\
\hline
\end{tabular}

Source: compiled by the authors

TABLE 6 Calculation table for determining the index of the educational component of the digital economy development

\begin{tabular}{|c|c|c|c|c|c|c|c|c|}
\hline Indicator & $\mathbf{E}_{1}$ & $\mathbf{E}_{2}$ & $\mathbf{E}_{3}$ & $\mathbf{E}_{4}$ & $\mathbf{E}_{5}$ & $\mathbf{E}_{6}$ & $\mathbf{E}_{7}$ & $\mathbf{E}_{8}$ \\
\hline $\bar{x}_{j}$ & 26,43 & 369,51 & 3602,96 & 245,06 & 9079,27 & 10,59 & 5,67 & 79,48 \\
\hline$S_{j}$ & 328,06 & 1867,99 & 29823,65 & 1509,59 & 21117,66 & 159,81 & 238,04 & 443,14 \\
\hline
\end{tabular}

Source: compiled by the authors 
TABLE 7 Point prediction for the determination of the projection data of partial indicators of the educational component index of the digital economy

\begin{tabular}{|c|c|c|c|c|c|c|c|c|}
\hline Year & $\mathbf{E}_{1}$ & $\mathbf{E}_{2}$ & $\mathbf{E}_{3}$ & $\mathbf{E}_{4}$ & $\mathbf{E}_{5}$ & $\mathbf{E}_{6}$ & $\mathbf{E}_{7}$ & $\mathbf{E}_{8}$ \\
\hline 2020 & 267 & 1030 & 21086 & 1678 & 43812 & 180 & 227 & 304 \\
\hline 2021 & 259 & 930 & 19853 & 1689 & 45522 & 182 & 226 & 287 \\
\hline 2022 & 252 & 830 & 18619 & 1699 & 47233 & 183 & 224 & 270 \\
\hline
\end{tabular}

Source: compiled by the authors

institutions which train postgraduate students, persons; $\mathrm{Er}_{7}$ - number of higher education institutions which train $\mathrm{PhD}$, persons; $\mathrm{Er}_{8}$ - number of students of higher education institutions calculated per 10000 of population.

It is also worth noting the adverse impact on the results of clustering the fact of the absence of statistical data in the Luhansk, Donetsk regions and the Autonomous Republic of Crimea. In addition, in order to prevent the clustering results from being distorted, statistical data in Kyiv were excluded from the initial information base.

In the course of using the k-means algorithm, average values of each of the indicators for each cluster are determined (see table 8).

Conducted calculations, iteration calculus made it possible to cluster the regions of Ukraine by the educational component of the digital economy development. Corresponding results are presented in table 9 and visualized in Figure 2.

In the whole set of partial parameters of the educational component of the digital economy development, we have identified three (number of higher education institutions of III-IV accreditation levels; number of students of higher education institutions of III-IV accreditation levels; number of employees involved in $\mathrm{R} \& \mathrm{D}$ conducting, who have completed higher education); based on that, Figure 3 was built. This figure allows positioning the regions of Ukraine in three-dimensional space of features in accordance with the dynamics of the selected parameters.

As it can be seen on the charts, the cluster of the regions with intensive development of the educational component of the digital economy include Zaporizhzhya, Odessa and Kharkiv regions; Kyiv, Kirovohrad, Donetsk, Lviv, Mykolaiv, Dnipropetrovsk and Sumy regions are related to the cluster of perspective regions with average development level; the rest of regions of Ukraine (15 regions which makes $62 \%$ of the analyzed regions) are included to the cluster of the regions with low development level of the parameters set of the educational component of the digital economy.

Therefore, summarizing the results of testing the methodological approach to assessing the impact of the educational component on the digital economy development, we can note that the dynamics of its structural components has a powerful effect on the digital economy development. This can be explained by the fact that the higher education system of the country is occupied by the vast majority of scientists, scientific and pedagogical workers, who represent the basic intellectual capital of the state. Contribution of higher education institutions in the analyzed context is systematized and can be represented by the following vectors:

a) training of scientific staff, as well as future specialists for digital economy;

b) preparation of a new generation of entrepreneurs capable of starting and operating businesses in the dynamic conditions of economic digitization (including the establishment of virtual enterprises);

c) carrying out research and innovation activities, including the generation of new ideas and their commercialization in the real economy.

Modern reform processes in the higher education system of the country are accompanied by a decrease in the number of educational institutions. These processes are aimed at consolidating universities, transforming them into regional centers of talent attraction; transformation into economic entities capable of attracting and effectively utilizing investment resources. In practice, the implementation of the aforementioned faces difficulties, its solution requires full consideration of the specific needs of individual regions of Ukraine. This applies both to the professional and qualification structure of specialists in demand in local

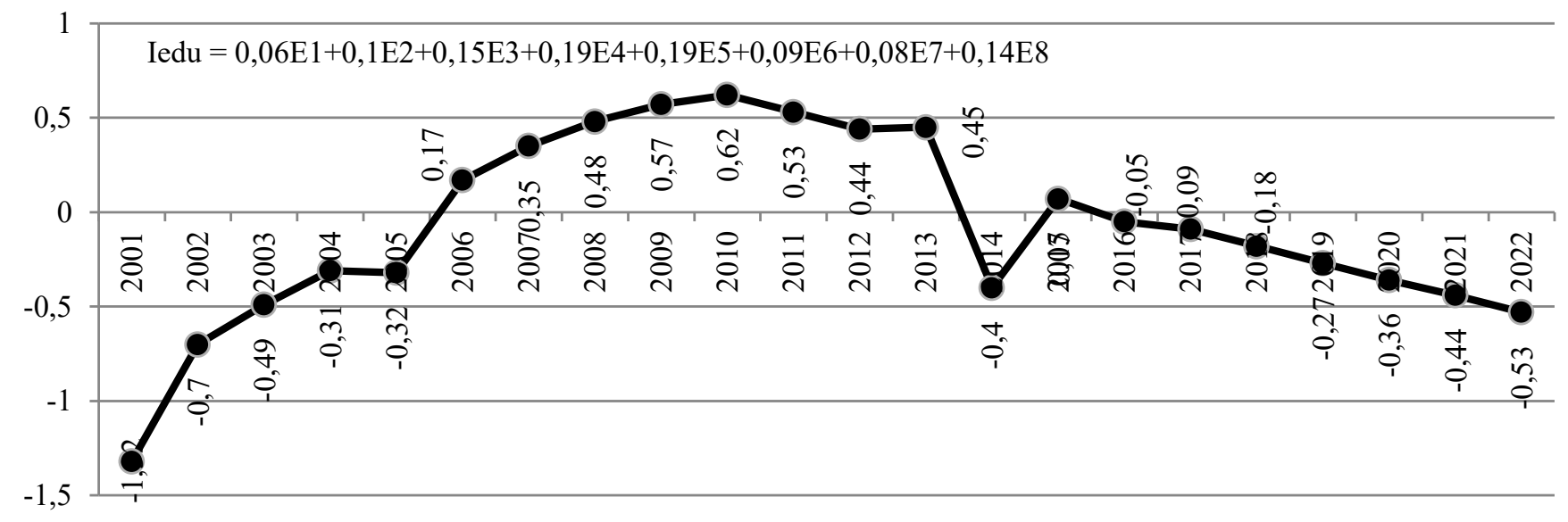

Source: compiled by the authors

FIGURE 1 Index dynamics of the educational component of the digital economy during 2001-2022 
TABLE 8 Average values of clusters by the educational component of the digital economy development

\begin{tabular}{|c|c|c|c|c|c|c|c|c|}
\hline Cluster & $\begin{array}{l}\text { Mean value } \\
\operatorname{Er}_{1}\end{array}$ & $\begin{array}{l}\text { Mean value } \\
\qquad \mathbf{E r}_{2}\end{array}$ & $\begin{array}{l}\text { Mean value } \\
\mathrm{Er}_{3}\end{array}$ & $\begin{array}{c}\text { Mean value } \\
\mathrm{Er}_{4}\end{array}$ & $\begin{array}{c}\text { Mean value } \\
\mathbf{E r}_{5}\end{array}$ & $\begin{array}{c}\text { Mean value } \\
\mathbf{E r}_{6}\end{array}$ & $\begin{array}{l}\text { Mean value } \\
\mathbf{E r}_{7}\end{array}$ & $\begin{array}{c}\text { Mean value } \\
\mathbf{E}_{8}\end{array}$ \\
\hline 1 & 8 & 36533 & 591 & 40 & 1732 & 7 & 11 & 288 \\
\hline 2 & 7 & 30023 & 445 & 27 & 679 & 4 & 6 & 296 \\
\hline 3 & 23 & 102875 & 1792 & 120 & 8895 & 22 & 35 & 477 \\
\hline
\end{tabular}

Source: compiled by the authors

TABLE 9 Results of clustering the regions of Ukraine by the educational component of the digital economy development

\begin{tabular}{|c|c|c|c|}
\hline Cluster & Number of regions & Regions & Description of the cluster \\
\hline 1 & 6 & Donetsk, Kyiv, Kirovohrad, Lviv, Mykolaiv, Sumy & $\begin{array}{l}\text { Perspective regions with an average level of the } \\
\text { development }\end{array}$ \\
\hline 2 & 15 & $\begin{array}{l}\text { Vinnytsia, Volyn, Dnipropetrovsk, Zhytomyr, Transcarpathia, } \\
\text { Ivano-Frankivsk, Luhansk, Poltava, Rivne, Ternopil, Kherson, } \\
\text { Khmelnytsk, Cherkasy, Chernivtsi, Chernihiv }\end{array}$ & $\begin{array}{l}\text { Regions with low levels of the educational } \\
\text { component development }\end{array}$ \\
\hline 3 & 3 & Odessa, Zaporizhzhia, Kharkiv & Regions with intensive development \\
\hline
\end{tabular}

Source: compiled by the authors

labor markets, as well as to the structure, profile orientation and qualitative effectiveness of the university research. Insufficient coherence of the state policy of optimization in the higher education system with meso-economic inquiries leads to the deepening of the imbalance in the processes of the digital economy formation at the regional level, breaking interconnections between higher education, business, government and society.

\section{Conclusions}

Significant reserves of activation of the digital economy development are concentrated in the higher education system (modern universities: consolidate powerful intellectual capital, train a generation of professionals, entrepreneurs of a new formation capable of thinking and acting in an innovative way, quickly adapting to dynamic changes of the economy; generate innovations, make scientific discoveries and inventions, the commercialization of which provides quality modernization of production processes of enterprises). Analysis of the parameters of the digital economy development in Ukraine made it possible to identify some problematic issues:

- finding the national economy only at the stage of becoming an digital economy;

- inconsistency in the development of digital economy components; presence of regional imbalances;

- incomplete use of the potential of educational, scientific and innovative organizations;

- underdeveloped cooperation between business, education, public and public sector entities;

- inefficiency of state funding for higher education, scientific, technical and innovative activities in the country;

- underdeveloped innovation infrastructure; outdated material and technical base of higher education institutions and scientific institutions;

- migration of perspective young people abroad (loss of intellectual potential);

- low prestige of educational and research activity in the society;

- low commercial attractiveness of the results of scientific research of universities;
- reduction of the global competitiveness of Ukrainian higher education institutions;

- high sensitivity of the index of educational component of the digital economy development to the influence of factors of the exogenous environment.

Solving these problems requires the development of scientifically sound strategic guidelines for enhancing the the digital economy development based on the optimization and effective utilization of existing potential of educational, scientific and innovative organizations. Emphasis should be placed on the synchronization of interests and integration of higher education institutions, business entities, the state and the public (Carayannis, Grigoroudis, 2016), that will stimulate the development and implementation of innovative research results of universities in the real economy and thus accelerate the pace of digital economy in the country. In turn, such integration requires the introduction of effective mechanisms for motivating businesses to participate in research and innovation activities of higher education institutions (the public sector) at the national level; development of a privileges system for innovative enterprises (business sector); providing targeted financing for the modernization of the logistics and innovation infrastructures of universities (higher education sector); introduction of a set of measures for the development of innovative culture in the society (public sector).

In our opinion, the activation of the processes of the digital economy formation in Ukraine requires deliberate state regulation and assistance. In particular, we have identified three main groups of measures of the state regulatory influence on subjects of the national economy:

- neutral-promoting influence of the state regulatory influence on the regions with intensive development of the educational component of the digital economy (focus on maintaining the positive dynamics of intensive development of the educational component of the digital economy), providing for stimulating the development of innovative, research and educational activities of universities; guaranteeing respect for intellectual property rights; deepening the cooperation between universities and enterprises; increased 


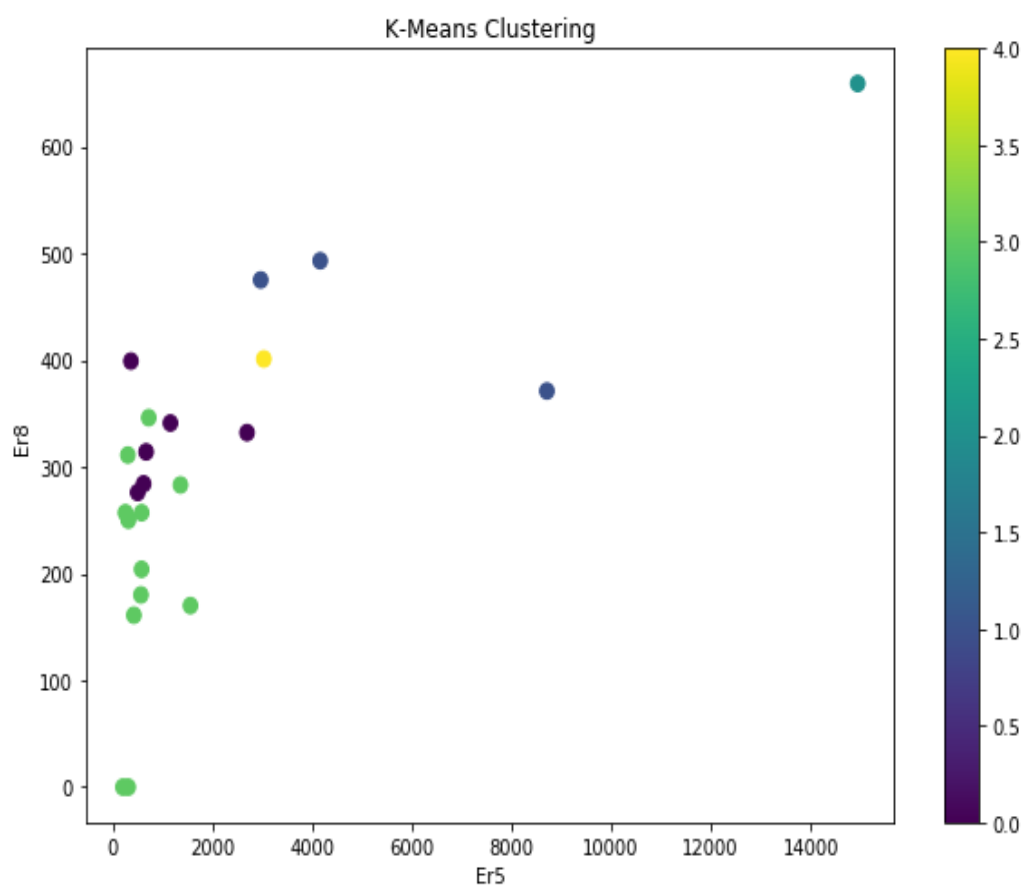

FIGURE 2 Results of regions clustering of Ukraine by the k-means algorithm - the educational component Source: compiled by the authors

support for innovatively active economic entities; enhancing the investment attractiveness of education and science;

- stimulating and supportive influence on perspective regions with average level of development (formation of effective motives for further structural changes of the educational component with sufficient financial, logistical, information, personnel support), which envisage an increase in the inflow of private investment in the development of the information and innovation infrastructure; formation of a comprehensive information-analytical fund with the inclusion of a reference apparatus and modern telecommunication networks in its structure; accelerating the pace of commercialization of the results of scientific research in higher education institutions;

- initiative-mentoring influence on the regions of the country with low level of the development of the digital economy and its educational component (creation of favorable conditions for launching modernization processes, support and coordination of their course), providing for the activities harmonization of higher

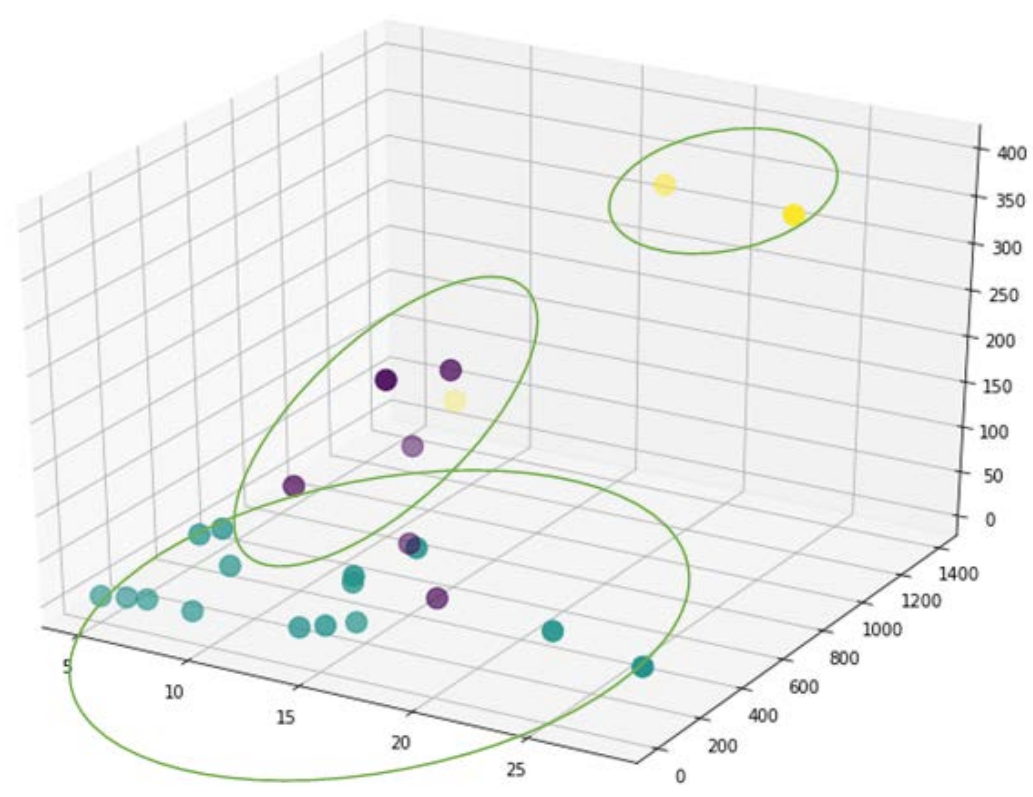

FIGURE 3 Visualization of clustering results on separate parameters of the educational component of the digital economy development Source: complied by the authors 
education institutions with the demands of the business sector; improving the quality of educational services; increasing the amount of investments in the upgrading of the educational and research facilities; increasing the pace of implementation of the latest information and communication technologies; development of digital literacy of the population, etc.
Implementation of the outlined above is a differentiated approach to activating the digital economy development, taking into consideration the impact of a set of exogenous and endogenous factors, and provided the optimum combination of the efforts of universities, public authorities, business sector and public organizations can become one of the major catalysts for the development of the national education system.

\section{References}

[1] Arthur, D., \& Vassilvitskii, S. (2006). How slow is the k-means method? In SCG '06: Proceedings of the twenty-second annual symposium on computational geometry. ACM Press. DOI: https://doi.org/10.1145/1137856.1137880

[2] Artuhur, D., \& Vassilvitskii, S. (2007). k-means++: The Advantages of Careful Seeding. Proceedings of the Eighteenth Annual ACM-SIAM Symposium on Discrete Algorithms, 1027-1035. DOI: https://doi.org/10.1145/1283383.1283494

[3] Bekkers, R., \& Bodas Freitas, I. (2008). Analyzing knowledge transfer channels between universities and industry: To what degree do sectors also matter? Research Policy, 37(10), 1837-1853. DOI: https://doi.org/10.1016/ j.respol.2008.07.007

[4] Bell, D. (1973). The Coming of Post-industrial Society: A Venture of Social Forecasting. New York: Basic Books, 507 p. E-source: https://www.os3.nl/_media/2011-2012/daniel_bell_-_the_coming_of_post-industrial_society.pdf

[5] Bottou, L., \& Bengio, Y. (1995). Convergence properties of the k-means algorithm. Advances in Neural Information Processing Systems. E-source: https://pdfs.semanticscholar.org/2352/d9105de31032538900dfb2ce7c95f6402963.pdf

[6] Carayannis, E., \& Grigoroudis, E. (2016). Quadruple Innovation Helix and Smart Specialization: Knowledge Production and National Competitiveness. Foresight and STI Governance, 10/1, 31-42. DOI: https://doi.org/10.17323/1995459x.2016.1.31.42

[7] Castells, M. (1997). The Information Age: Economy, Society and Culture: The Power of Identity. Oxford: Blackwell. DOI: https://doi.org/10.1177/0739456X9901900212

[8] Cosmulese, C. G., Grosu, V., Hlaciuc, E., \& Zhavoronok, A. (2019). The Influences of the Digital Revolution on the Educational System of the EU Countries. Marketing and Management of Innovations, 3, $242-254$. DOI: http://doi.org/10.21272/mmi.2019.3-18

[9] Dubrov, A. M., Mxytaryan, V. S., \& Troshyn, L. Y. (1998). Mnogomernye statystycheskye metody [Multidimensional statistical methods]. Moscow: Fynansy i statystyka. (in Russian)

[10] Elkan, C. (2003). Using the triangle inequality to accelerate k-means. Proceedings of the Twentieth International Conference on Machine Learning, 3, 147-153. E-source: https://dl.acm.org/doi/10.5555/3041838.3041857

[11] Har-Peled, S., \& Sadri, B. (2005). How fast is the k-means method? SODA'05: Proceedings of the sixteenth annual ACM-SIAM symposium on Discrete algorithms, 877-885, Philadelphia, PA, USA. DOI: https://doi.org/10.1007/s00453004-1127-9

[12] Hartigan, J. A., \& Wong, M. A. (1979). A k-means clustering algorithm. Applied Statistics, 28, $100-108$. DOI: https://doi.org/10.2307/2346830

[13] Ivanov, Yu., \& Tyshchenko, V. (2015). Public-private partnership potential in knowledge economy: regional aspect. Economic Annals-XXI, 3-4(1), 28-31. E-source: http://soskin.info/userfiles/file/2015/3-4_1_2015/Ivanov,\%20 Tyshchenko.pdf

[14] Jain, A. J., Murty, M. N., \& Flynn, P. J. (1999). Data clustering: a review. ACM Computing Surveys, 31/3, 264-323. DOI: https://doi.org/10.1145/331499.331504

[15] Kanungo, T., Mount, D. M., Netanyahu, N. S., Piatko C. D., Silverman R., \& Wu A. Y. (2004). A local search approximation algorithm for k-means clustering. Comput. Geom, 28(2-3), 89-112. E-source: https://www.cs.umd.edu/ mount/Projects/ KMeans/kmlocal-cgta.pdf

[16] Kym, Dzh.-O. (1989). Faktornyj, dyskrymynantnyj y klasternyj analyz [Factorial, discriminant and cluster analysis]. Moscow: Finances and statistics.

[17] Masuda, Y. (1983). The Information Society as Postindustrial Society. Washington: Word Future Soc., 45.

[18] Pankaj, K. Agarwal, \& Nabil H. Mustafa (2004). K-means projective clustering. PODS '04: Proceedings of the twenty-third ACM SIGMOD-SIGACT-SIGART symposium on Principles of database systems. 155-165, New York, NY, USA. ACM Press. DOI: https://doi.org/10.1145/1055558.1055581

[19] Porat, Mark U. (1977). The Digital economy. Nine volumes. Office of Telecommunication, US Department of Commerce. Washington.

[20] Prokopenko, I. F., \& Ganin, V. I. (2008). Metodyka i metodologiya ekonomichnogo analizu [Methodology and methodology of economic analysis]. Kyiv: Center for Educational Literature. (in Ukrainian)

[21] Saaty, T. (1980). The Analytic Hierarchy Process: Planning, Priority Setting, Resource Allocation. McGraw-Hill. E-source: https://www.scirp.org/(S(lz5mqp453edsnp55rrgjct55))/reference/References Papers.aspx?ReferenceID=1943982

[22] Sculley, D. (2010). Web Scale K-Means Clustering. Proceedings of the 19th International Conference on World Wide Web. 1177-1178. DOI: https://doi.org/10.1145/1772690.1772862

[23] Wu, X., \& Kumar, V. (2009). The Top Ten Algorithms in Data Mining. Chapman \& Hall. CRC. DOI: https://doi.org/10.1007/ s10115-007-0114-2 